\title{
Evaluation of healing of pressure ulcers through thermography: a preliminary study
}

Maria Emília Abreu Chaves*, Fernanda Souza da Silva, Viviane Pinheiro Campos Soares, Rafael Augusto Magalhães Ferreira, Flávia Sampaio Latini Gomes, Roberto Márcio de Andrade, Marcos Pinotti

\begin{abstract}
Introduction: Thermography is a surface thermal radiation measurement technique whose application has been expanding in the healthcare field. The unhealed wound is a serious public health problem because it intervenes in the quality of life of patients and may cause emotional and psychological losses. The wound temperature can provide quantitative data that allow for the healing process to be monitored. The aim of this study was to verify whether thermography can be used as a method to evaluate the healing of pressure ulcers. Methods: Eight participants with sacral pressure ulcers were recruited and randomly divided into two groups: A (control) and B (experimental). Both groups received standard treatment for a period of four weeks, which consisted of a daily cleaning of the pressure ulcers with physiological saline (sodium chloride $0.9 \%$ ) followed by an alginate hydrogel dressing. The group B received light-emitting diode (LED) phototherapy in addition to standard treatment, three times a week, yielding a total of 12 sessions. Photographs and thermograms of each pressure ulcer were obtained in all sessions in both groups. Results: Pressure ulcers treated with LED phototherapy were healed. The pressure ulcer area of group B decreased over the 12 treatment sessions, whereas the pressure ulcer area of group A increased. The ulcer temperature of group B was higher than that of group A during the treatment (temperature difference up to 7.6\%). Discussion: The present study suggests a relationship between the temperature and area of pressure ulcers and proposes thermography as an adjunctive method for the evaluation of healing processes.
\end{abstract}

Keywords: Thermography, Wound healing, Pressure ulcer.

\section{Introduction}

Thermography is a measurement technique that quantifies body surface temperature by capturing the thermal radiation emitted by the body and thereby produces a digital image. The captured radiation is converted to an electrical signal, forming an image in which the results are expressed in gray levels or in color. The thermogram shows a distribution of colors on the surface of a body, allowing for the evaluation and quantification of temperature (Calado et al., 2014).

This technique is an objective method for identifying objects that are not illuminated and diagnose structures and industrial equipment based on the surface temperature of structures in the analyzed environments (Andrade and Eduardo, 2011). Moreover, studies show that thermography has been expanding in the healthcare field in recent years. The technique is a safe, effective and reliable method for the examination of the human body. The advantages of this technique are that it is noninvasive, it is a quick method for diagnosing diseases, no patient contact is required, it does not inflict any pain, it does not require the use of contrasts and it is inexpensive. The equipment is portable, and the information is available in real time (Bronzino, 2006; Yamamoto et al., 2013).

Currently, thermography is used in many specialized healthcare fields, including oncology (Zore et al., 2013), rheumatology (Frize and Ogungbemile, 2012), orthopedics (Haddad et al., 2012), neonatal medicine (Abbas et al., 2011) and neurology (Saito et al., 2000). Thermography has been used to monitor pain (Bostock et al., 2005), inflammation (Christensen et al., 2012), respiratory disease (Rich et al., 2004), vascular diseases (Huang et al., 2011) and wound healing (Nagase et al., 2011; Nakagami et al., 2010).

Healing is crucial to the survival and quality of life of humans and animals (Vermolen and Javierre, 2010). It is a complex process, and there are numerous factors, local or systemic, that can interfere with tissue repair, resulting in delays, in poor aesthetic appearance and in increased morbidity and mortality of patients (Perricone, 1999; Young and McNaught, 2011).

According to the literature, the population is subject to ulceration, with an increased prevalence among elderly people (Skene et al., 1992). In the United 
States, it is estimated that 1.3 million to 3 million adults have a pressure ulcer, with an estimated cost of $\$ 500$ to $\$ 40,000$ required to heal each ulcer (Lyder, 2003). In Brazil, statistical data about the incidence and prevalence of chronic wounds and public spending are rare in the literature. However, the care of patients with such conditions is quite common in dermatology, vascular medicine, plastic surgery and physiotherapy services (Datasus, 2012). Thus, the unhealed wound represents a serious public health problem.

It has been shown that physical conditions such as diabetes mellitus, obesity, malnutrition, old age (over 60), decreased perfusion, malignancy, organ failure, sepsis, and even restrictions in mobility have an impact on healing. Furthermore, wound-related factors such as ulcer size (over $2 \mathrm{~cm}^{2}$ ), duration (over two months) and ulcer depth (penetration through to exposed tendon, ligament, bone or joint) are the most important factors for predicting patient outcomes (European..., 2008). Studies have also shown that the probability of healing increases with a decrease in the size and depth of pressure ulcers (Kramer and Kearney, 2000).

According to International EPUAP-NPUAP (European... 2009), pressure ulcers are classified into four categories. Category I: intact skin with nonblanchable erythema of a localized area usually over a bony prominence. Discoloration of the skin, warmth, edema, hardness or pain may also be present. Darkly pigmented skin may not show visible blanching. Category II: partial thickness loss of dermis presenting as a shallow open ulcer with a red-pink wound bed, without slough. The ulcer may also present as an intact or open/ruptured serum-filled or serosanguinous filled blister. Category III: full thickness tissue loss. Subcutaneous fat may be visible, but bone, tendon or muscle are not exposed. Some slough may be present. The ulcer may also show undermining and tunneling. Category IV: full thickness tissue loss with exposed bone, tendon or muscle. Slough or eschar may be present. The ulcer often shows undermining and tunneling.

The most reliable indicator of healing is the percentage of wound area reduction, which refers to the diminishment of wound area relative to that measured on day zero (Robson et al., 2000). However, this approach requires longitudinal observation (Nakagami et al., 2010). Real-time evaluation is necessary to identify and monitor the healing results of a treatment (Nakagami et al., 2010). However, it is difficult to precisely quantify wound healing.

Based on literature findings, the measured temperature of a wound could be an indicator of wound healing (Garcia and Siddiqui, 2012; Kateb et al., 2009; Nakagami et al., 2010; Sayre et al., 2007;
Yamamoto et al., 2013). According to Rocha (2009), there is an optimum temperature range for healing to occur such that temperatures outside this range may lead to a delay in the healing process.

The present study aims to verify whether thermography can be used as a method for evaluating the healing of pressure ulcers.

\section{Methods}

\section{Study design}

This study protocol was approved by the Research Ethics Committee, Universidade Federal de Minas Gerais (UFMG), Belo Horizonte, Brazil (approval No. CAAE 04110812600005149).

Participants were recruited between September and December 2013 at a hospital in Belo Horizonte, Brazil. The inclusion criteria were pressure ulcers located in the sacral region, without clinical signs of infection, and ages between 40 and 80 years. Sacral pressure ulcers were chosen because of the high incidence of these wounds in the hospital.

The exclusion criteria were diabetes, development of infection during treatment, pregnancy, presence of cancer, photosensitivity or any adverse reactions under exposure to sunlight.

\section{Protocol}

The participants who met the inclusion criteria were randomly divided into two groups: A (control) and $\mathrm{B}$ (experimental). Identification tags corresponding to group A or B were placed in sealed unmarked envelopes and shuffled. The number of envelopes was the same for both groups. With each new participant who entered the study, an envelope was randomly selected and opened, with the participant being duly assigned to either group A or B. The standard treatment was applied in groups A and B. Light-emitting diode (LED) phototherapy alone was used in group B.

The standard treatment consisted of a daily cleaning of the pressure ulcers with physiological saline (sodium chloride $0.9 \%$ ) followed by an alginate hydrogel dressing over a period of 4 weeks.

LED phototherapy was applied through a prototype featuring a cluster of $60 \mathrm{LED}$ lights $(30 \mathrm{red}$ and 30 infrared) arranged in concentric circles. The prototype was developed by the company SEVA Electronic Engineering. The parameters used were wavelengths of 660 and $940 \mathrm{~nm}$, continuous emission mode and an irradiation dose of $4 \mathrm{~J} / \mathrm{cm}^{2}$. The prototype was controlled by a software program that estimated the time of application based on the selected dose. The phototherapy was applied three times a week over a period of four weeks, yielding 12 sessions 
for each participant. The parameters selected for the prototype were based on a literature review concerning the biological effects (Agnol et al., 2009; Lanzafame et al., 2007; Tada et al., 2009) of LED phototherapy on wound healing.

\section{Evaluation of pressure ulcers area}

Photographs of each pressure ulcer were captured three times a week over 12 sessions using a Nikon ${ }^{\circledR}$ D5100 camera with an 18-55 mm lens. A Vernier Caliper $^{\circledR}$ with a measuring range of $0-150 \mathrm{~mm}$ was used to measure each ulcer. The digital images were analyzed by the software program Quantikov, version 8.12 , which calculated the pressure ulcer area.

\section{Thermographic evaluation}

Thermograms of each pressure ulcer were obtained three times a week over 12 sessions. A FLIR I60 ${ }^{\circledR}$ thermographic camera with a $180 \times 180$ pixel IR resolution, a spectral range of 7.5 to $13 \mu \mathrm{m}$ and a thermal sensitivity $<0.1{ }^{\circ} \mathrm{C}$ at $25^{\circ} \mathrm{C}$ was used for thermographic evaluation.

The thermograms were captured after removing the dressing before the standard treatment or application of phototherapy. Each participant was placed in the lateral decubitus position, and the thermographic camera was positioned perpendicular to the pressure ulcer at a distance of 15 or $20 \mathrm{~cm}$ depending on the pressure ulcer size.

The ambient temperature and relative humidity were previously measured using a FLUKE ${ }^{\circledR} 971$ digital hygrometer with a precision of $\pm 0.5^{\circ} \mathrm{C}$. The reflected average temperature was considered equal to ambient temperature. The emissivity value adopted was similar to the dermis emissivity value $(0.98)$ reported in the literature (Bernard et al., 2013).

\section{Uncertainty analysis}

The calculations of the temperature presented in this study were initially performed by the software FLIR Therma CAM Researcher to obtain the coordinates of a given point. This point was selected to be in the center of the pressure ulcer, disregarding regions of moisture. The FLIR Therma CAM Researcher exported a file .mat for the software Thermography Measurement Uncertainty developed in MATLAB (Teixeira, 2012).

This program was a systematized routine calculation according to the GUM (Guide to the Expression of Uncertainty in Measurement) method, which should be proportional to the array of radiation signals and analyzes the uncertainty of the temperature measurement, taking the coordinates of the measurement point, the distance, the ambient temperature, the reflected average temperature and emissivity of the skin as input (Table 1).

\section{Results}

The sample of this study consisted of eight participants with a sacral pressure ulcer, who were divided into two groups according to the type of treatment: A (control) and B (experimental). The clinical characteristics of both groups of participants, such as age, ulcer classification, duration of ulcer and initial ulcer size, are presented in Table 2.

Table 1. Values of uncertainty of input data.

\begin{tabular}{lcc}
\hline \multicolumn{1}{c}{ Parameter } & Uncertainty & Assumed distribution \\
\hline Emissivity & \pm 0.01 & Rectangular \\
Temperature & $\pm 0.5^{\circ} \mathrm{C}$ & Rectangular \\
Average temperature reflected & $\pm 0.5^{\circ} \mathrm{C}$ & Rectangular \\
Distance & $\pm 0.01 \mathrm{~m}$ & Rectangular \\
\hline
\end{tabular}

Table 2. Clinical characteristics of the participants.

\begin{tabular}{lcc}
\multicolumn{1}{c}{ Characteristic } & Group A & Group B \\
\hline Number of participants & 4 & 4 \\
Age in years (mean $\pm \mathrm{SD})$ & $60.8 \pm 21.1$ & $60.3 \pm 15.3$ \\
Range & $41-80$ & $40-77$ \\
Ulcer classification & & $0 \%$ \\
Category I & $0 \%$ & $25 \%$ \\
Category II & $50 \%$ & $50 \%$ \\
Category III & $25 \%$ & $25 \%$ \\
Category IV & $25 \%$ & $10.3 \pm 9.7$ \\
Duration of ulcer in months (mean $\pm \mathrm{SD})$ & $20.3 \pm 20.8$ & $2-24$ \\
Range $($ months) & $2-48$ & $55.7 \pm 13.7$ \\
Initial ulcer size in $\mathrm{cm}^{2}($ mean $\pm \mathrm{SD})$ & $52.3 \pm 16.1$ & $44.8-73.3$ \\
Range $\left(\mathrm{cm}^{2}\right)$ & $35.2-71.3$ & \\
\hline
\end{tabular}


In this study, Table 2 shows that the factors age and initial ulcer size were similar between the two groups of participants. There were small differences between groups A and B with respect to ulcer classification and duration of ulcer, which can be justified by randomization.

Figure 1 shows the evolution of pressure ulcers in both groups, specifically in sessions 1, 6 and 12 . Figures $1 \mathrm{a}, 1 \mathrm{~b}$, and $1 \mathrm{c}$ represent a participant from group A, whereas Figures 1d, 1e, and 1f represent a participant from group B. It can be observed that the pressure ulcer of the participant form group A increased in area and depth in the $6^{\text {th }}$ session (Figure 1b). In addition, the depth increased further in the $12^{\text {th }}$ session (Figure 1c). The pressure ulcer of the participant from group B showed an improvement with respect to local irrigation, the formation of granulation tissue and reduction in area in the $6^{\text {th }}$ (Figure 1e) and $12^{\text {th }}$ session (Figure 1f).

Figure 2 represents the difference between the measured ulcer area in the initial session and that measured in the final session for both groups. For group A, there was an increase between the area at the beginning and at the end of the intervention period. For group B, the area at the end of the treatment was smaller than that at the beginning.
Figure 3 shows the evolution of pressure ulcers in groups $\mathrm{A}$ and $\mathrm{B}$ over the 12 treatment sessions. The pressure ulcer area in group A increased, whereas the pressure ulcer area in group B decreased.

Figure 4 shows the temperature of pressure ulcers in groups A and B over the 12 treatment sessions. The uncertainty in the temperature measurements was $\pm 1{ }^{\circ} \mathrm{C}$. Participants from both groups presented ulcer temperatures within the appropriate range for healing. According to Rocha (2009), the appropriate temperature for healing occurs between $32^{\circ} \mathrm{C}$ to $36^{\circ} \mathrm{C}$.

Figure 5 shows the percentage difference in temperature of pressure ulcers between group $B$ and group $\mathrm{A}$. The trend line indicates that the percentage difference between groups A and B increased with the number of sessions. The temperature difference between groups B and A ranged from 1.9\% to 7.6\% during the treatment.

\section{Discussion}

The healing of pressure ulcers treated with LED phototherapy and alginate hydrogel dressing (group B) cannot be attributed to possible differences in the clinical characteristics of participants because the two groups had similar characteristics (Table 2). Moreover,

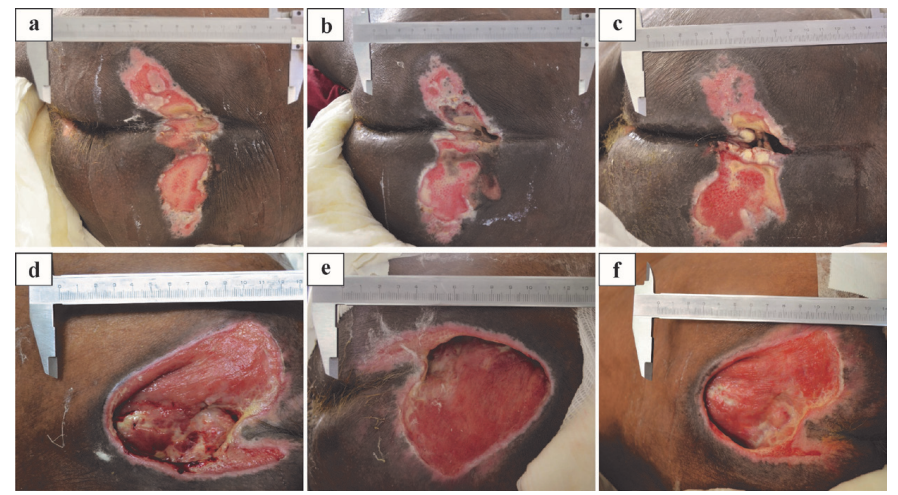

Figure 1. Comparative image of pressure ulcers in both groups.
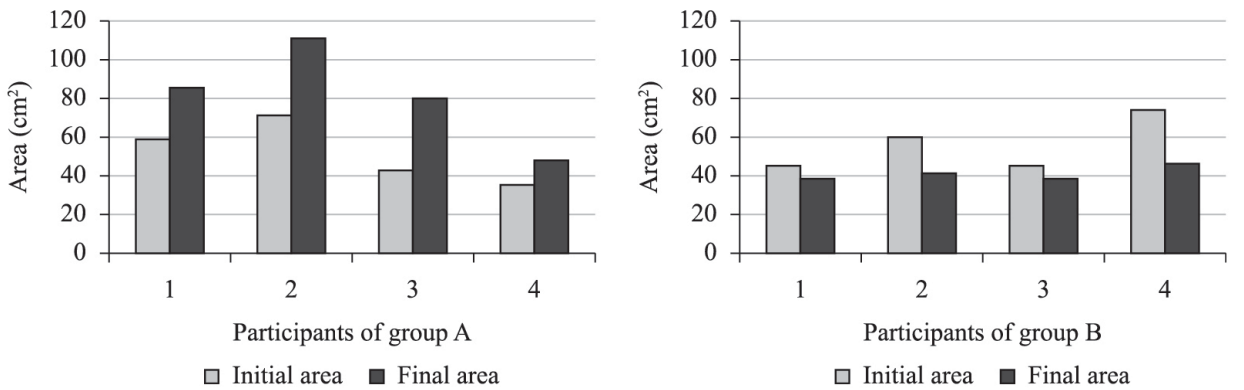

Figure 2. Initial and final ulcer area in groups A and B. 


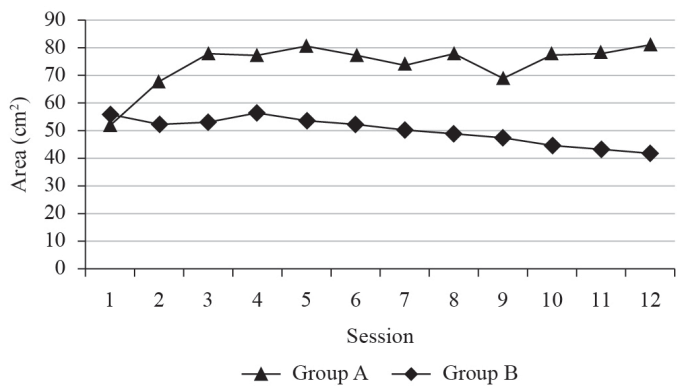

Figure 3. Average area of pressure ulcers during treatment in groups $\mathrm{A}$ and $\mathrm{B}$.

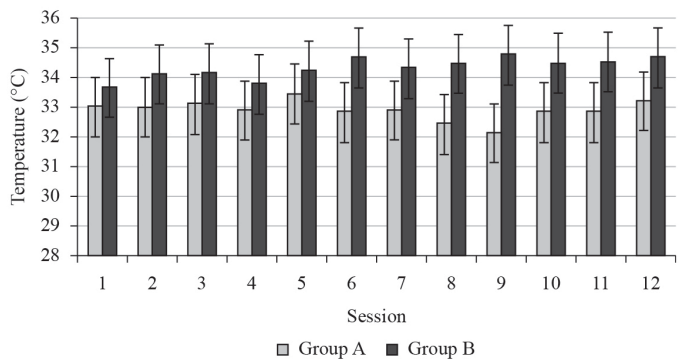

Figure 4. Average temperature $\left( \pm 1{ }^{\circ} \mathrm{C}\right)$ of pressure ulcers during treatment in groups A and B.

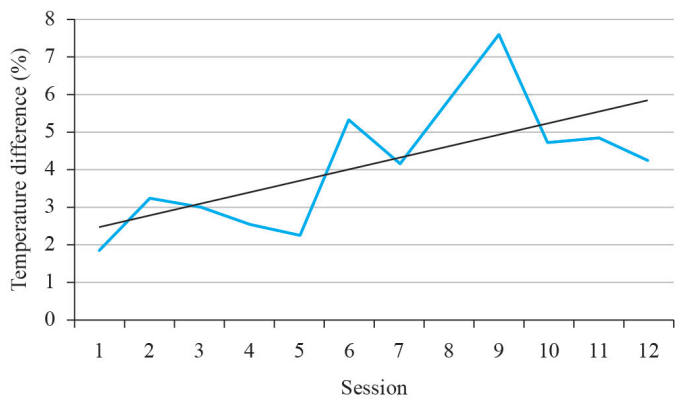

Figure 5. Temperature difference (\%) of pressure ulcers.

the same inclusion and exclusion criteria were used to admit both groups of participants into the study.

Figure 1 shows differences between participants in the two groups. The participant from group B showed an improvement in local irrigation, formation of granulation tissue and reduction in area. Furthermore, in comparing the last session to the initial session, all participants in group B showed a reduction in pressure ulcer area, unlike the participants in group A, who showed an increase in pressure ulcer area (Figure 2). Similar results have been observed in other studies (Caetano et al., 2009; Erdle et al., 2008; Minatel et al., 2009; Whelan et al., 2003;).

Group B showed a reduction in area over the course of the treatment period, whereas group A did not (Figure 3). The discrepancy may be explained by the fact that group B received phototherapy in addition to the standard treatment.
Our results are in accord with those reported in other studies in the literature, which indicate that LED phototherapy promotes wound healing due to the physiological effects of phototherapy, such as stimulation of ATP synthesis, increased fibroblast proliferation, collagen production and stimulation of angiogenesis (Corazza et al., 2007; Karu, 2003; Sousa et al., 2010).

The results of our study also indicate that the temperature of pressure ulcers was within the appropriate range for healing $\left(32^{\circ}-36^{\circ} \mathrm{C}\right)$ in both groups (Figure 4$)$. All cellular functions are affected by temperature, including chemical reactions (metabolism, protein synthesis and oxidation) and phagocytosis, mitosis and locomotion (Bryant and Nix, 2012).

However, when comparing the two groups, group A demonstrated a lower pressure ulcer temperature $\left(32-33{ }^{\circ} \mathrm{C}\right)$ than did group $\mathrm{B}\left(34-35{ }^{\circ} \mathrm{C}\right)$ during the treatment. The difference in temperature between the two groups reached up to $7.6 \%$ (Figure 5).

Analysis of the results revealed that participants in group A showed an increase in wound area and a low pressure ulcer temperature, whereas those in group B showed a decrease in wound area and a high pressure ulcer temperature. This observation suggests a relationship between the wound area and temperature of pressure ulcers.

It should be noted that this study was limited by its small sample size and the lack of studies about thermography and wound healing. However, the results of this study suggest a relationship between area and temperature variations of pressure ulcers. Therefore, thermography may be considered a suitable adjunctive method for the evaluation of the wound healing process.

In future studies, we suggest verifying the validity of the findings presented herein, applying the methodology to a larger number of participants. We also suggest executing the protocol in another anatomical region or on another type of wound, e.g., venous ulcers, and observing whether there are significant changes in temperature.

\section{Acknowledgements}

The authors would like to thank Lucas Alfredo Queiroz Silva and Henry Fabrício Pimenta Martins of the company SEVA Electronic Engineering.

\section{References}

Abbas AK, Heimann K, Jergus K, Orlikowsky T, Leonhardt $\mathrm{S}$. Neonatal non-contact respiratory monitoring based on real-time infrared thermography. Biomedical Engineering Online 2011; 10(1):93. http://dx.doi.org/10.1186/1475925X-10-93. PMid:22243660 
Agnol MA, Nicolau RA, Lima CJ, Munin E. Comparative analysis of coherent light action (laser) versus non-coherent light (light-emitting diode) for tissue repair in diabetic rats. Lasers in Medical Science 2009; 24(6):909-16. http://dx.doi. org/10.1007/s10103-009-0648-5. PMid:19238507

Andrade RM, Eduardo AC. Methodology for automatic process of the fired ceramic tile's internal defect using IR images and artificial neural network. Journal of the Brazilian Society of Mechanical Sciences and Engineering 2011; 33(1):6773. http://dx.doi.org/10.1590/S1678-58782011000100010.

Bernard V, Staffa E, Mornstein V, Bourek A. Infrared camera assessment of skin surface temperature: effect of emissivity. Physica Medica 2013; 29(6):583-91. http:// dx.doi.org/10.1016/j.ejmp.2012.09.003. PMid:23084004

Bostock H, Campero M, Serra J, Ochoa JL. Temperaturedependent double spikes in C-nociceptors of neuropathic pain patients. Brain 2005; 128(Pt 9):2154-63. http://dx.doi. org/10.1093/brain/awh552. PMid:15947060

Bronzino JD. Medical devices and systems. Boca Raton: CRC Press; 2006. http://dx.doi.org/10.1201/9781420003864.

Bryant RA, Nix DP. Acute and chronic wounds: current management concepts. 4th ed. St. Louis: Elsevier Mosby; 2012.

Caetano KS, Frade MA, Minatel DG, Santana LA, Enwemeka CS. Phototherapy improves healing of chronic venous ulcers. Photomedicine and Laser Surgery 2009; 27(1):111-8. http://dx.doi.org/10.1089/pho.2008.2398. PMid:19196110

Calado CR, Calado FAR, Caput G, Gomes SC, Andrade RM. Porosity and delamination defect detection in ceramic materials by active infrared thermography and optical digital microscopy. Materials Science Forum 2014; 798799:671-6. http://dx.doi.org/10.4028/www.scientific.net/ MSF.798-799.671.

Christensen J, Matzen LH, Vaeth M, Schou S, Wenzel A. Thermography as a quantitative imaging method for assessing postoperative inflammation. Dento Maxillo Facial Radiology 2012; 41(6):494-9. http://dx.doi.org/10.1259/ dmfr/98447974. PMid:22752326

Corazza AV, Jorge J, Kurachi C, Bagnato VS. Photobiomodulation on the angiogenesis of skin wounds in rats using different light sources. Photomedicine and Laser Surgery 2007; 25(2):102-6. http://dx.doi.org/10.1089/pho.2006.2011. PMid:17508845

Datasus. [cited 2012 July 11]. Available from: http://www. datasus.gov.br/.

Erdle BJ, Brouxhon S, Kaplan M, Vanbuskirk J, Pentland AP. Effects of continuous-wave (670-nm) red light on wound healing. Dermatologic Surgery 2008; 34(3):320-5. PMid:18177400.

European Pressure Ulcer Advisory Panel - EPUAP. National Pressure Ulcer Advisory Panel - NPUAP. Treatment of pressure ulcers: quick reference guide. Washington: National Pressure Ulcer Advisory Panel; 2009.

European Wound Management Association - EWMA. Position document: hard-to-heal wounds. A holistic approach. London: MEP Ltd; 2008.
Frize M, Ogungbemile A. Estimating rheumatoid arthritis activity with infrared image analysis. Studies Health Technolology Informactcs 2012; 180:594-8. PMid:22874260.

Garcia A, Siddiqui A. Pressure ulcers: the role of thermography and the need to revisit staging. Ostomy/Wound Management 2012; 58(12):10. PMid:23392647.

Haddad DS, Brioschi ML, Arita ES. Thermographic and clinical correlation of myofascial trigger points in the masticatory muscles. Dento Maxillo Facial Radiology 2012; 41(8):621-9. http://dx.doi.org/10.1259/dmfr/98504520. PMid:23166359

Huang CL, Wu YW, Hwang CL, Jong YS, Chao CL, Chen WJ, Wu YT, Yang WS. The application of infrared thermography in evaluation of patients at high risk for lower extremity peripheral arterial disease. Journal of Vascular Surgery 2011; 54(4):1074-80. http://dx.doi.org/10.1016/j. jvs.2011.03.287. PMid:21784604

Karu TI. Low-power laser therapy. In: Vo-Dinhed T. Biomedical Photonics Handbook. Florida: CRC Press; 2003.

Kateb B, Yamamoto V, Yu C, Grundfest W, Gruen JP. Infrared thermal imaging: a review of the literature and case report. NeuroImage 2009; 47(2, Suppl 2):T154-62. http://dx.doi. org/10.1016/j.neuroimage.2009.03.043. PMid:19332140

Kramer JD, Kearney M. Patient, wound, and treatment characteristics associated with healing in pressure ulcers. Advances in Skin \& Wound Care 2000; 13(1):17-24. PMid:11061706.

Lanzafame RJ, Stadler I, Kurtz AF, Connelly R, Peter TA, Brondon P, Olson D. Reciprocity of exposure time and irradiance on energy density during photoradiation on wound healing in a murine pressure ulcer model. Lasers in Surgery and Medicine 2007; 39(6):534-42. http://dx.doi. org/10.1002/1sm.20519. PMid:17659591

Lyder CH. Pressure ulcer prevention and management. Journal of the American Medical Association 2003; 289(2):223-6. http://dx.doi.org/10.1001/jama.289.2.223. PMid:12517234

Minatel DG, Frade MAC, França SC, Enwemeka CS. Phototherapy promotes healing of chronic diabetic leg ulcers that failed to respond to other therapies. Lasers in Surgery and Medicine 2009; 41(6):433-41. http://dx.doi. org/10.1002/1sm.20789. PMid:19588536

Nagase T, Sanada H, Takehara K, Oe M, Iizaka S, Ohashi Y, Oba M, Kadowaki T, Nakagami G. Variations of plantar thermographic patterns in normal controls and non-ulcer diabetic patients: novel classification using angiosome concept. Journal of Plastic, Reconstructive \& Aesthetic Surgery 2011; 64(7):860-6. http://dx.doi.org/10.1016/j. bjps.2010.12.003. PMid:21257357

Nakagami G, Sanada H, Iizaka S, Kadono T, Higashino T, Koyanagi H, Haga N. Predicting delayed pressure ulcer healing using thermography: a prospective cohort study. Journal of Wound Care 2010; 19(11):465-6. http://dx.doi. org/10.12968/jowc.2010.19.11.79695. PMid:21135794

Perricone N. How to approach acute and chronic wound healing in the elderly. Wounds 1999; 11(6):145-51. 
Rich PB, Dulabon GR, Douillet CD, Listwa TM, Robinson WP, Zarzaur BL, Pearlstein R, Katz LM. Infrared thermography: a rapid, portable, and accurate technique to detect experimental pneumothorax. The Journal of Surgical Research 2004; 120(2):163-70. http://dx.doi.org/10.1016/j. jss.2004.02.026. PMid:15234209

Robson MC, Hill DP, Woodske ME, Steed DL. Wound healing trajectories as predictors of effectiveness of therapeutic agents. Archives of Surgery 2000; 135(7):773-7. http:// dx.doi.org/10.1001/archsurg.135.7.773. PMid:10896369

Rocha CLJV. Histophysiology and classification of burn: consequences of local systems and tissue loss in patients burnt. Revista Interdisciplinar de Estudos Experimentais 2009; 1(3):140-7.

Saito H, Omura K, Tateyama M. Alternating monomeric paresis with decreased skin temperature and hyperhidrosis in a case of thoracolumbar myelopathy. Clinical Autonomic Research 2000; 10(2):77-80. http://dx.doi.org/10.1007/ BF02279895. PMid:10823339

Sayre EK, Kelechi TJ, Neal D. Sudden increase in skin temperature predicts venous ulcers: a case study. Journal of Vascular Nursing 2007; 25(3):46-50. http://dx.doi. org/10.1016/j.jvn.2007.06.002. PMid:17723909

Skene AI, Smith JM, Doré CJ, Charlett A, Lewis JD. Venous leg ulcers: a prognostic index to predict time to healing. British Medical Journal 1992; 305(6862):1119-21. http:// dx.doi.org/10.1136/bmj.305.6862.1119. PMid:1463945

Sousa AP, Santos JN, Reis JA Jr, Ramos TA, Souza J, Cangussú MCT, Pinheiro ALB. Effect of LED phototherapy of three distinct wavelengths on fibroblasts on wound healing: a histological study in a rodent model. Photomedicine and
Laser Surgery 2010; 28(4):547-52. http://dx.doi.org/10.1089/ pho.2009.2605. PMid:20001321

Tada K, Ikeda K, Tomita K. Effect of polarized light emitting diode irradiation on wound healing. The Journal of Trauma Injury Infection and Critical Care 2009; 67(5):1073-9. http:// dx.doi.org/10.1097/TA.0b013e318187ad02. PMid:19680158

Teixeira GGD. Metrological reliability in thermography applied for electrical systems [dissertation]. Belo Horizonte: Universidade Federal de Minas Gerais; 2012.

Vermolen FJ, Javierre E. Computer simulations from a finite-element model for wound contraction and closure. Journal of Tissue Viability 2010; 19(2):43-53. http://dx.doi. org/10.1016/j.jtv.2009.11.003. PMid:20022249

Whelan HT, Buchmann EV, Dhokalia A, Kane MP, Whelan NT, Wong-Riley MTT, Eells JT, Gould LJ, Hammamieh R, Das R, Jett M. Effect of NASA light-emitting diode irradiation on molecular changes for wound healing in diabetic mice. Journal of Clinical Laser Medicine \& Surgery 2003; 21(2):67-74. http://dx.doi.org/10.1089/104454703765035484. PMid:12737646

Yamamoto T, Yamamoto N, Azuma S, Todokoro T, Koshima I. Handy thermography for bedside evaluation of pressure ulcer. Journal of Plastic, Reconstructive \& Aesthetic Surgery 2013; 66(7):e205-6. http://dx.doi.org/10.1016/j. bjps.2013.02.005. PMid:23481580

Young A, McNaught C. The physiology of wound healing. Surgery $2011 ; 29(10): 475-9$.

Zore Z, Boras I, Stanec M, Oresić T, Zore IF. Influence of hormonal status on thermography findings in breast cancer. Acta Clinica Croatica 2013; 52(1):35-42. PMid:23837271.

\footnotetext{
Authors

Maria Emília Abreu Chaves ${ }^{1 *}$, Fernanda Souza da Silva², Viviane Pinheiro Campos Soares², Rafael Augusto Magalhães Ferreira ${ }^{2}$, Flávia Sampaio Latini Gomes ${ }^{3}$, Roberto Márcio de Andrade ${ }^{2}$, Marcos Pinotti ${ }^{1}$ ${ }^{1}$ Bioengineering Laboratory, Department of Mechanical Engineering, Universidade Federal de Minas Gerais - UFMG, Av. Presidente Antônio Carlos, 6627, CEP 31270-010, Belo Horizonte, MG, Brazil.

${ }^{2}$ Thermometry Laboratory, Department of Mechanical Engineering, Universidade Federal de Minas Gerais - UFMG, Belo Horizonte, MG, Brazil.

${ }^{3}$ Basic Nursing Department, School of Nursing, Universidade Federal de Minas Gerais - UFMG, Belo Horizonte, MG, Brazil.
} 